University of Nebraska - Lincoln

DigitalCommons@University of Nebraska - Lincoln

USDA National Wildlife Research Center - Staff Publications
U.S. Department of Agriculture: Animal and Plant Health Inspection Service

2013

\title{
Optimizing line intercept sampling and estimation for feral swine damage levels in ecologically sensitive wetland plant communities
}

\author{
Jacob F. Thomas \\ University of Colorado at Denver and Health Sciences Center \\ Richard M. Engeman \\ USDA-APHIS-Wildlife Services, s_r100@yahoo.com
}

Eric A. Tillman

USDA/APHIS/WS National Wildlife Research Center, eric.a.tillmann@aphis.usda.gov

Justin W. Fischer

USDA/APHIS/WS National Wildlife Research Center, Justin.w.fischer@aphis.usda.gov

Steve L. Orzell

Avon Park Air Force Range, steve.orzell@avonpark.macdill.af.mil

See next page for additional authors

Follow this and additional works at: https://digitalcommons.unl.edu/icwdm_usdanwrc

Part of the Life Sciences Commons

Thomas, Jacob F.; Engeman, Richard M.; Tillman, Eric A.; Fischer, Justin W.; Orzell, Steve L.; Glueck, Deborah H.; Felix, Rodney K.; and Avery, Michael L., "Optimizing line intercept sampling and estimation for feral swine damage levels in ecologically sensitive wetland plant communities" (2013). USDA National Wildlife Research Center - Staff Publications. 1197.

https://digitalcommons.unl.edu/icwdm_usdanwrc/1197

This Article is brought to you for free and open access by the U.S. Department of Agriculture: Animal and Plant Health Inspection Service at DigitalCommons@University of Nebraska - Lincoln. It has been accepted for inclusion in USDA National Wildlife Research Center - Staff Publications by an authorized administrator of DigitalCommons@University of Nebraska - Lincoln. 


\section{Authors}

Jacob F. Thomas, Richard M. Engeman, Eric A. Tillman, Justin W. Fischer, Steve L. Orzell, Deborah H. Glueck, Rodney K. Felix, and Michael L. Avery 


\title{
Optimizing line intercept sampling and estimation for feral swine damage levels in ecologically sensitive wetland plant communities
}

\author{
Jacob F. Thomas $\cdot$ Richard M. Engeman • \\ Eric A. Tillman • Justin W. Fischer • Steve L. Orzell • \\ Deborah H. Glueck • Rodney K. Felix • Michael L. Avery
}

Received: 12 April 2012 / Accepted: 21 May 2012 / Published online: 17 June 2012

(C) Springer-Verlag (outside the USA) 2012

This article is a U.S. government work, and is not subject to copyright in the United States.

\begin{abstract}
Ecological sampling can be labor intensive, and logistically impractical in certain environments. We optimize line intercept sampling and compare estimation methods for assessing feral swine damage within fragile wetland ecosystems in Florida. Sensitive wetland sites, and the swine damage within them, were mapped using GPS technology. Evenly spaced parallel transect lines were simulated across a digital map of each site. The length of each transect and total swine damage under each transect were measured and percent swine damage within each site was estimated by two methods. The total length method (TLM) combined all transects as a single long transect, dividing the sum of all damage lengths across all transects by the combined length
\end{abstract}

Responsible editor: Zhihong Xu

J. F. Thomas • D. H. Glueck

Department of Biostatistics, Colorado School of Public Health, University of Colorado Denver,

Historic Building 500, 13001 E. 17th Place, Mail Stop C245,

Aurora, CO 80045, USA

R. M. Engeman $(\bowtie) \cdot J$. W. Fischer

USDA/APHIS/WS National Wildlife Research Center,

4101 LaPorte Ave,

Fort Collins, CO 80521-2154, USA

e-mail: richard.m.engeman@aphis.usda.gov

E. A. Tillman $\cdot$ R. K. Felix $\cdot$ M. L. Avery

Florida Field Station, USDA/APHIS/WS National Wildlife

Research Center,

2820 E University Blvd,

Gainesville, FL 32641, USA

S. L. Orzell

Avon Park Air Force Range,

29 South Blvd.,

Avon Park AFR, FL 33825, USA of all transect lines. The equal weight method (EWM) calculated the damage proportion for each transect line and averaged these proportions across all transects. Estimation was evaluated using transect spacings of $1,3,5,10,15$, and $20 \mathrm{~m}$. Based on relative root mean squared error and relative bias measures, the TLM produced higher quality estimates than EWM at all transect spacings. Estimation quality decreased as transect spacing increased, especially for TLM. Estimation quality also increased as the true proportion of swine damage increased. Diminishing improvements in estimation quality as transect spacings decreased suggested $5 \mathrm{~m}$ as an optimal tradeoff between estimation quality and labor. An inter-transect spacing of $5 \mathrm{~m}$ with TLM estimation appeared an optimal starting point when designing a plan for estimating swine damage, with practical, logistical, economic considerations determining final design details.

Keywords Environmental sampling $\cdot$ Feral hog $\cdot$ Invasive species $\cdot$ Seepage slope $\cdot$ Sus scrofa $\cdot$ Wet flatwoods .

Comparative accuracy

\section{Introduction}

Researchers and managers face many challenges when conducting efficient but valid ecological sampling. Environments physically difficult to sample and resource limitations in personnel or materials can place practical restrictions on sample sizes and sampling methods, thereby putting a premium on methodological ease for obtaining samples. Also, the act of sampling in highly valued habitats, such as fragile wetlands or specialty crops, can potentially be destructive or impractical in 
some sites. Thus, optimizing the quality of estimation with labor, cost effectiveness, and environmental impacts in acquiring data is vital for sampling-sensitive sites.

The need for practical, reduced-labor ecological sampling procedures, and accompanying analytical methods that yield quality estimates of the environmental parameters has sparked much research over the years, and has resulted in development of sampling procedures and estimation methods for a variety of applications. For example, the search for reduced-labor methods produced the general field and the many methods within it for plotless density sampling and estimation (e.g., Engeman et al. 1994; Pielou 1977). In the present research we focus on the tradeoff between estimate quality and sampling effort as we examine sampling and estimation methods for assessing feral swine damage to fragile wetland habitats, a problem of widespread interest around the world. Moreover, such methodology potentially could be applied to many other environmental sampling situations as well.

Wetland habitats in Florida have a long history of destruction. For example, only $1 \%$ of the original extent of seepage slopes in Florida remain (Florida Natural Areas Inventory 2010). Adding to the problem of habitat loss, feral swine (Sus scrofa) are ubiquitous in Florida, and wreak considerable damage to imperiled wetland habitats, primarily through rooting of the native groundcover vegetation (e.g., Engeman et al. 2003, 2004, 2007; Seward et al. 2004). Feral swine damage is most pronounced in wet environments (e.g., Choquenot et al. 1996), and swine have been implicated as the single greatest vertebrate modifier of natural plant communities (Bratton 1977; Wood and Barrett 1979). While swine population monitoring is valuable for determining management efficacy (e.g., Engeman et al. 2001, 2007), it is the amount of damage to habitat that determines the need for and efficacy of swine management programs (e.g., Engeman et al. 2007).

The Avon Park Air Force Range (APAFR) in southcentral Florida contains ecologically sensitive wetland plant communities of global significance (Orzell 1997), and swine damage to those communities prompted a multi-year swine removal program (USDA/Wildlife Services/National Wildlife Research Center 2009). In December 2008, efforts were initiated to assess the extent of swine damage within selected sensitive plant community sites on APAFR. Global positioning system (GPS) technology enabled entire sensitive plant sites to be mapped, as well as areas of damage within each site (USDA/Wildlife Services/National Wildlife Research Center 2009). A thorough search of entire sites can be intensive, time consuming, and costly. Thus, there is a need to identify labor-saving, low-impact sampling methods for measuring damage coupled with analytical procedures yielding quality estimates of damage. Geographic information system (GIS) maps of swine damage at APAFR formed the bases for Monte Carlo simulations of line intercept sampling to identify the optimal tradeoffs between sampling intensity (transect spacing, which determines labor, cost, and environmental damage) and damage level estimation quality. We also examined alternative damage estimation calculations to determine which provided the greatest accuracy and precision. Because swine damage varies in patch size, shape, and distribution, our results will not only be useful for swine damage situations on a global scale, but will also provide valuable direction for other environmental sampling applications.

\section{Methods}

\section{Avon Park Air Force Range}

The APAFR is a US Air Force military installation (42,930 ha) located in Polk and Highland Counties in south-central Florida $\left(27^{\circ} 35^{\prime} \mathrm{N}, 81^{\circ} 16^{\prime} \mathrm{W}\right)$, and contains 23,600 ha of intact natural habitats (Orzell 1997). The region has a seasonal subtropical climate with a pronounced wet and dry season (Slocum et al 2010). The base is used for military training, although approximately 33,180 ha are open to public recreation, including hunting. The Air Force manages the natural resources of APAFR to support military readiness and to ensure mission sustainability. A variety of seasonal wetland plant communities found on the base are highly sensitive to ground disturbance (e.g., seepage slopes, wet flatwoods, wet prairies, and peaty marshes) and harbor many rare and endemic plants (Florida Natural Areas Inventory 2010; Harper et al. 1998; Orzell 1997). The impact of feral hogs on natural resources is a serious ecological management issue at APAFR, and monitoring swine damage is a means to assess the efficacy of management actions (USDA/Wildlife Services/National Wildlife Research Center, 2009).

\section{GIS mapping and measurements}

We mapped a subset of APAFR's sensitive plant communities and all swine damage within these sites in January 2009. This required an intensive search of each site to locate all damage and record damage patch perimeters using a Trimble GeoExplorer XT GPS units (Trimble Navigation Ltd., Sunnyvale, CA, USA) equipped with TerraSync software (Trimble Navigation Ltd., Sunnyvale, CA, USA). GPS data were recorded at 1-s intervals and had post-processing accuracy (using Trimble Pathfinder Office software; Trimble Navigation Ltd., Sunnyvale, CA, USA) $\leq 1.0 \mathrm{~m}$.

We sampled nine mapped wetland sites to assess sampling and estimation procedures (Table 1). The total area of each site, as well as the individual areas of the damage patches within each site were determined using ArcMap 
Table 1 Characteristics of nine wetland sites on Avon Park Air Force Range mapped and digitally sampled for feral swine damage using line intercept sampling

\begin{tabular}{llll}
\hline Site ID & Wetland type & Size (ha) & Proportion damaged \\
\hline 1 & Seepage slope & 11.5 & 0.0332 \\
2 & Seepage slope & 9.6 & 0.0516 \\
3 & Wet flatwoods & 3.3 & 0.0033 \\
4 & Seepage slope & 10 & 0.0598 \\
5 & Seepage slope & 13.2 & 0.0177 \\
6 & Wet flatwoods & 0.8 & 0.0617 \\
7 & Seepage slope & 9.8 & 0.0005 \\
8 & Seepage slope & 9.8 & 0.0394 \\
9 & Wet flatwoods & 6 & 0.0394 \\
\hline
\end{tabular}

9.2 software (ArcMap; Environmental Systems Research Institute, Redlands, CA, USA).

Knowing the actual amount of damage within each site and the total area of each site enabled optimization of sampling intensities and comparison among damage estimation methods using Monte Carlo techniques. Simulated sampling was conducted within each site using evenly spaced, parallel transect lines simulated across the digital map of each site, from one boundary line to the other. Transect lines were spaced $1 \mathrm{~m}$ apart along the longest axis of a site using ArcMap (Fig. 1). The lengths of each transect line and damage patch intercepted by each transect line were also calculated using ArcMap. The total length of damage for a transect was summed from the combined lengths of all damage patches intercepted by the transect. A database was developed for each site containing lengths of each transect at 1-m spacing paired with total length of damage patches intercepted by the corresponding transect. These formed the basic data sets from which sampling could be optimized and estimation methods compared.

Simulated sampling and estimation method assessment

Two methods to estimate percent of damage within each site were considered. The first, identified as the total length method (TLM), treated all transects as if they comprised a single long transect. Thus, the sum of total damage lengths
Fig. 1 Sensitive plant community site 6 (smallest site sampled) showing the mapping of the site perimeter (bold black line) and each of the feral swine damage patches (highly variable shaped, grey areas), overlaid with parallel line intercept sampling transects spaced $1 \mathrm{~m}$ apart

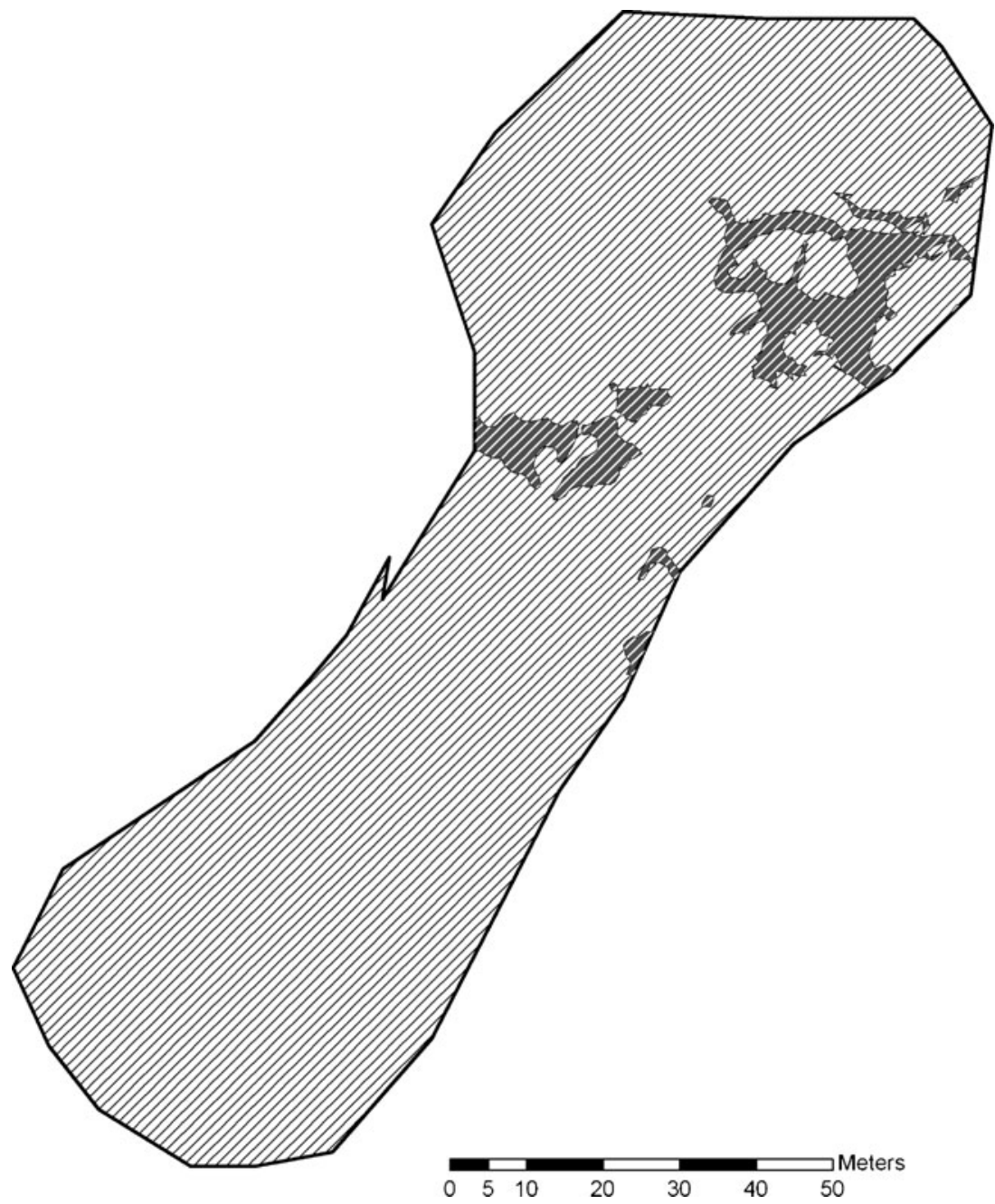


across all transects was divided by the total length of all transect lines combined. The second method, or equal weight method (EWM), had each transect contributing equally to the estimate. The proportion of damage under each transect line was calculated by dividing the sum of the damage lengths under a transect by that transect's total length. These damage proportions from each transect were then averaged across all transects. The two estimation procedures are summarized in the following equations. For $n$ transects traversing a plant community site,

$$
\begin{gathered}
\stackrel{\stackrel{\wedge}{P}}{\text { TLM }}=\sum_{i=1}^{n} \sum_{j=1}^{m_{i}} d_{i j} / \sum_{i=1}^{n} t_{i} \\
\stackrel{\stackrel{\wedge}{P}}{\mathrm{EWM}}=\frac{1}{n} \sum_{i=1}^{n}\left(\sum_{j=1}^{m_{i}} d_{i j}\right) / t_{i},
\end{gathered}
$$

where $t_{i}=$ the length of the $i$ th transect, $d_{i j}=$ the length of the $j$ th damaged intercept on the $i$ th transect, and $m_{i}=$ the number of damage patches intercepted by the $i$ th transect.

The amount of space between each transect is of particular interest, since greater spacing means less labor, lower costs, and less environmental damage. Spacings of 1, 3, 5, 10,15 , and $20 \mathrm{~m}$ were assessed. Data for each of these intertransect spacings were readily available since data had been generated at every meter. For 3-m spacing, data from every third transect line was used. This yielded three line intercept samples for each site corresponding to the three potential start points, which could begin either with the first potential transect line $(1,4,7, \ldots \mathrm{m}$ from the starting edge $)$, the second potential line $(2,5,8, \ldots \mathrm{m}$ from the starting edge $)$, or the third potential line $(3,6,9, \ldots \mathrm{m}$ from the starting edge). Similarly, the 5-m inter-transect spacing yielded five line intercept samples for each site, and so on for the other intertransect spacings. For each sample and spacing, two estimates of damage proportion were calculated using the TLM and EWM methods.

The relative root mean squared error (RRMSE) was used as the primary criteria for comparing performance of estimates because it encompasses variance and bias, and it is unitless (Engeman et al. 1994; Engeman and Sugihara 1998; Nielson et al. 2004; Patil et al. 1979; White et al. 2008). RRMSE was calculated as

RRMSE $=\left\{\left[\sum(\stackrel{\wedge}{P}-P)^{2} / P^{2}\right] / I\right\}^{1 / 2}$,

where $\stackrel{\wedge}{P}$ was the estimated damage proportion, $P$ was the true damage proportion, and $I$ was the number of iterations for each sample spacing (i.e., a transect spacing of $3 \mathrm{~m}$ would have three iterations, and so forth). Therefore, for each site, the RRMSE was calculated for each combination of estimation method (TLM and EWM) and transect spacing
$(1,3,5,10,15$, and $20 \mathrm{~m})$, for a total of 12 RRMSE statistics per site. Similarly, the relative bias (RBIAS), the mean observed bias divided by the true parameter value, was also calculated for each transect spacing and estimation method combination for each site.

Summary data for the RRMSE and RBIAS were tabulated and graphed to visualize which estimation method yielded the best estimates of damage for each inter-transect spacing, and at what fineness of transect spacing diminishing improvements were observed in estimation quality. A mixed effects model was applied to examine how RRMSE was influenced by transect spacing and estimation procedure. The interaction term between spacing and estimation method was of particular interest to see if the relationship between the RRMSE and spacing differed between estimation methods. Estimation method and sample spacing were repeated fixed factors within sites (random effect), and a Kronecker covariance structure was used to model the variance-covariance structure of the data across estimation method and sample spacing, with the outcome variable, RRMSE, log-transformed to account for right skew and non-linearity. For both estimation methods, a mixed effects analysis with transect spacing as a repeated measure within sites assessed the association between RRMSE and the true percent of damage at the sites. Mixed effect analyses were conducted using SAS PROC MIXED (Littell et al. 1996; SAS Inc. Version 9.2, Cary, NC, USA). To better assess the expected diminishing estimation improvements as sampling intensity increased (i.e., as inter-transect spacing decreased), we graphed RRMSE against transect density (which equals $1 /$ transect spacing) for both estimation methods, and fit exponential decay curves to the data (using PROC GPLOT, SAS Inc. Version 9.2, Cary, NC, USA).

\section{Results}

Our assessment of nine sites with six different transect spacings and two estimation methods resulted in the calculation of 108 RRMSEs (Table 2), and RBIAS's (Table 3), from which a number of important estimation patterns emerged. The TLM clearly produced higher quality estimates than EWM. The TLM RRMSE values were consistently and considerably lower than EWM values for all sites and spacing combinations, except for site 7 at wider transect spacings $(10,15$, and $20 \mathrm{~m})$, and site 3 where results from the two estimation methods were nearly equal (Tables 2 and 3). Estimation quality decreased as the sample spacing increased for TLM, while still superior to EWM at all spacings. The RRMSE for most sites showed little variability across transect spacings for the EWM. However, for sites 3 and 7 the RRMSE noticeably increased for EWM as the transect spacing increased (Table 2). For the TLM, sites 3 
Table 2 Relative root mean squared error results from Monte Carlo simulations assessing transect spacing and two analytical methods (total length method and equal weight method) for estimating the amount of feral swine damage within nine GIS-mapped sensitive plant sites at Avon Park Air Force Range, Florida using line intercept sampling

\begin{tabular}{lllllllllll}
\hline Transect spacing & Estimation method & Site 1 & Site 2 & Site 3 & Site 4 & Site 5 & Site 6 & Site 7 & Site 8 & Site 9 \\
\hline \multirow{2}{*}{$1 \mathrm{~m}$} & TLM & 0.007 & $7.03 \mathrm{E}-05$ & 0.018 & 0.001 & 0.007 & 0.009 & 0.037 & $6.65 \mathrm{E}-05$ & 0.006 \\
& EWM & 0.379 & 0.208 & 0.019 & 0.224 & 0.359 & 0.363 & 0.275 & 0.259 & 0.192 \\
$\mathrm{~m}$ & TLM & 0.014 & 0.003 & 0.169 & 0.010 & 0.016 & 0.059 & 0.084 & 0.012 & 0.012 \\
& EWM & 0.380 & 0.208 & 0.165 & 0.224 & 0.359 & 0.365 & 0.280 & 0.259 & 0.192 \\
$\mathrm{~m}$ & TLM & 0.026 & 0.003 & 0.146 & 0.004 & 0.038 & 0.046 & 0.159 & 0.018 & 0.025 \\
& EWM & 0.380 & 0.208 & 0.141 & 0.224 & 0.361 & 0.364 & 0.295 & 0.260 & 0.193 \\
$10 \mathrm{~m}$ & TLM & 0.031 & 0.019 & 0.323 & 0.037 & 0.051 & 0.169 & 0.491 & 0.049 & 0.083 \\
& EWM & 0.380 & 0.209 & 0.311 & 0.227 & 0.363 & 0.381 & 0.442 & 0.261 & 0.203 \\
& TLM & 0.088 & 0.070 & 0.531 & 0.097 & 0.130 & 0.151 & 1.136 & 0.066 & 0.049 \\
$20 \mathrm{~m}$ & EWM & 0.384 & 0.217 & 0.531 & 0.237 & 0.367 & 0.372 & 0.830 & 0.263 & 0.195 \\
& TLM & 0.118 & 0.092 & 0.603 & 0.119 & 0.075 & 0.235 & 0.901 & 0.087 & 0.102 \\
& EWM & 0.389 & 0.237 & 0.552 & 0.243 & 0.366 & 0.402 & 0.686 & 0.264 & 0.214 \\
\hline
\end{tabular}

and 7 had noticeably higher RRMSE's at each transect spacing in comparison to other sites, especially at the wider transect spacings. This pattern was evident for the EWM only at the widest transect spacings for these two sites (Table 2). The two estimation methods had nearly equivalent RRMSEs only for site 3 at every inter-transect spacing. This site was quite rectangular in shape, making transect lengths relatively constant. For fixed transect lengths the two estimation procedures become identical (Eqs. 1 and 2). No other sites shared this feature.

The patterns that emerged for RBIAS (Table 3) were similar to those found for RRMSE (Table 2) in that TLM had substantially less bias than EWM at almost every site and spacing combination. In contrast to the pattern in Table 2, the RBIAS for both estimation methods stayed nearly constant as sample spacing increased, whereas in Table 2 the RRMSE followed this pattern only for EWM. The magnitudes of RBIAS for the EWM were very close to those for RRMSE at each site and transect spacing combination (except for sites 3 and 7), demonstrating that estimation variability using the EWM resulted mostly from bias.

Increased estimation quality would be expected with increased sampling intensity (decreased inter-transect spacing). We also considered the matter of identifying when the magnitude of such improvements in estimation quality diminishes sufficiently to make increases in sampling intensity impractical. This was most readily observed by relating RRMSE to the density of transects (the inverse of intertransect spacing), where diminishing returns were wellrepresented as exponential decays as sampling intensity
Table 3 Relative bias results from Monte Carlo simulations assessing transect spacing and two analytical methods (total length method and equal weight method) for estimating the amount of feral swine damage within nine GIS-mapped sensitive plant sites at Avon Park Air Force Range, Florida using line intercept sampling

\begin{tabular}{|c|c|c|c|c|c|c|c|c|c|c|}
\hline Transect spacing & Estimation method & Site 1 & Site 2 & Site 3 & Site 4 & Site 5 & Site 6 & Site 7 & Site 8 & Site 9 \\
\hline \multirow[t]{2}{*}{$1 \mathrm{~m}$} & TLM & -0.007 & $-7.03 \mathrm{E}-05$ & 0.018 & 0.001 & -0.007 & 0.009 & 0.037 & $-6.65 \mathrm{E}-05$ & -0.006 \\
\hline & EWM & -0.379 & 0.208 & -0.019 & -0.224 & -0.359 & -0.363 & -0.275 & -0.259 & -0.192 \\
\hline \multirow[t]{2}{*}{$3 \mathrm{~m}$} & TLM & -0.006 & $-6.97 \mathrm{E}-05$ & 0.018 & 0.001 & -0.005 & 0.009 & 0.037 & $-6.56 \mathrm{E}-05$ & -0.006 \\
\hline & EWM & -0.379 & 0.208 & -0.019 & -0.224 & -0.359 & -0.363 & -0.275 & -0.259 & -0.192 \\
\hline \multirow[t]{2}{*}{$5 \mathrm{~m}$} & TLM & -0.006 & $-7.06 \mathrm{E}-05$ & 0.018 & 0.001 & -0.007 & 0.009 & 0.037 & $-6.36 \mathrm{E}-05$ & -0.006 \\
\hline & EWM & -0.379 & 0.208 & -0.018 & -0.224 & -0.360 & -0.363 & -0.275 & -0.259 & -0.192 \\
\hline \multirow[t]{2}{*}{$10 \mathrm{~m}$} & TLM & -0.007 & $-7.03 \mathrm{E}-05$ & 0.017 & 0.001 & -0.007 & 0.014 & 0.038 & $1.91 \mathrm{E}-06$ & -0.006 \\
\hline & EWM & -0.379 & 0.208 & -0.019 & -0.223 & -0.360 & -0.361 & -0.271 & -0.259 & -0.192 \\
\hline \multirow[t]{2}{*}{$15 \mathrm{~m}$} & TLM & -0.006 & $1.66 \mathrm{E}-04$ & 0.012 & 4.72E-04 & -0.007 & 0.006 & 0.038 & $-4.17 \mathrm{E}-06$ & -0.006 \\
\hline & EWM & -0.380 & 0.207 & -0.018 & -0.223 & -0.360 & -0.366 & -0.285 & -0.259 & -0.192 \\
\hline \multirow[t]{2}{*}{$20 \mathrm{~m}$} & TLM & -0.006 & $3.59 \mathrm{E}-04$ & 0.012 & 0.001 & -0.007 & 0.014 & 0.031 & $3.16 \mathrm{E}-06$ & -0.006 \\
\hline & EWM & -0.379 & 0.209 & -0.035 & -0.224 & -0.360 & -0.361 & -0.277 & -0.260 & -0.192 \\
\hline
\end{tabular}


Fig. 2 The relationship between frequency of line intercept transects (inverse of transect spacing) and relative root mean squared error (RRMSE) when using the total length method for estimating the amount of feral swine damage within nine GISmapped sensitive plant sites at Avon Park Air Force Range, Florida using line intercept sampling. The fitted exponential decay line is shown

\section{Total Length Method}

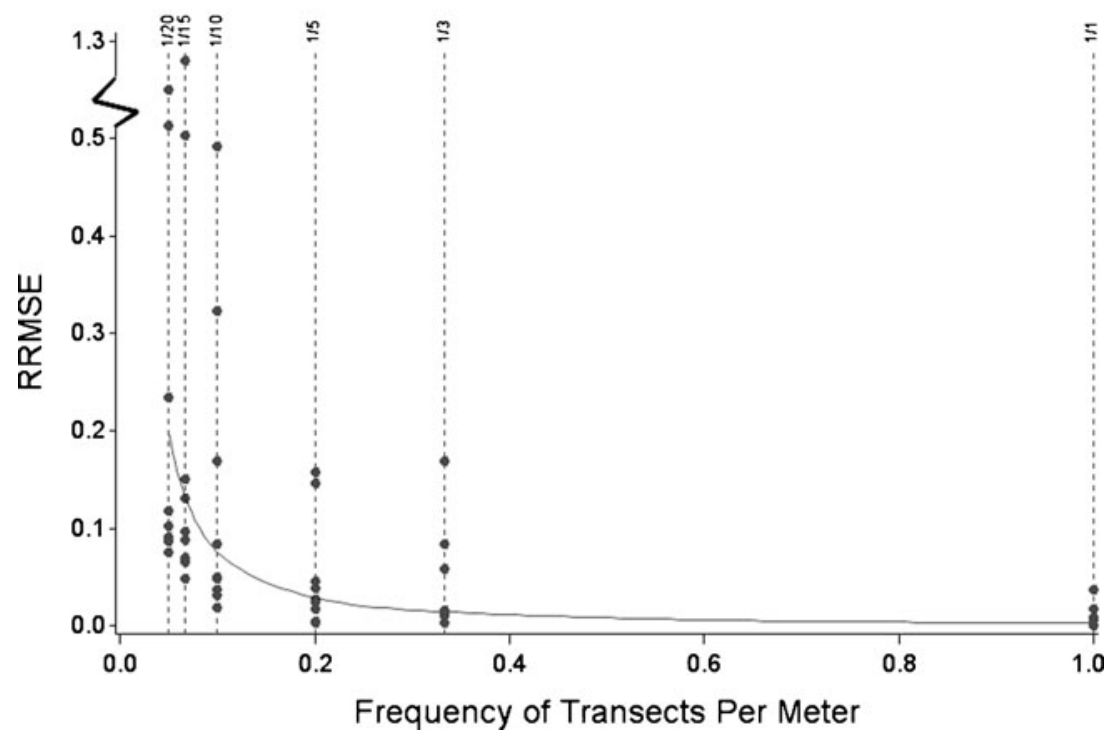

increased, or equivalently, as inter-transect spacing decreased (Figs. 2 and 3).

There was an interaction between transect spacing and estimation method $\left(F_{1,96}=20.39, p<0.0001\right)$, as RRMSE for the TLM increased with spacing width, while it remained fairly constant (and higher) for the EWM across intertransect spacings. On average, for every $1 \mathrm{~m}$ increase in sample spacing, the RRMSE increased $20 \%$ using the TLM, compared to $3 \%$ for EWM.

There was a strong inverse relationship between RRMSE and true damage proportion $\left(F_{1,7}=30.08, p=\right.$ 0.0009 ) for TLM, where, on average, for every $1 \%$ increase in the true damage proportion, RRMSE decreased by $34.5 \%$. The two sites with the smallest true damage (sites 3 and 7) produced the highest RRMSEs at all inter-transect spacings for the TLM method (Table 2). However, a similar relationship between the RRMSE and the true damage proportion was not evident for $\operatorname{EWM}\left(F_{1,7}=0.19, p=0.67\right)$, probably because other factors besides true damage level had greater influence on estimation quality, such as shape of the site being sampled.

\section{Discussion}

There are many factors to consider in ecological sampling, as the quality and quantity of data may be counterbalanced by costs, labor, and potential sampling impacts. Thus, sampling procedures that minimize labor coupled with analytical
Fig. 3 The relationship between frequency of line intercept transects (inverse of transect spacing) and relative root mean squared error (RRMSE) when using the equal weight method for estimating the amount of feral swine damage within nine GISmapped sensitive plant sites at Avon Park Air Force Range, Florida using line intercept sampling. The fitted exponential decay line is shown

\section{Equal Weight Method}

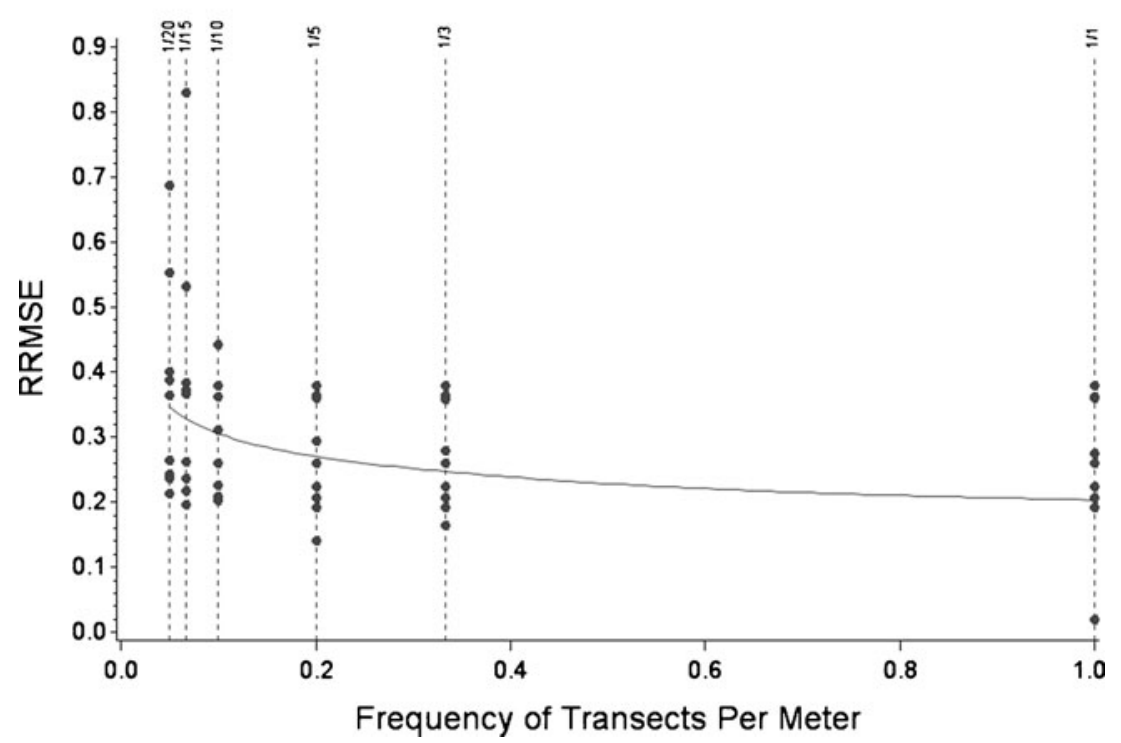


procedures that yield quality estimates of the environmental parameters of interest are valuable tools for researchers and managers alike. This need is exemplified when assessing swine damage in imperiled wetlands of Florida. The damage levels within these vulnerable habitats determine the need for and ultimately gauge the efficacy of swine management programs, thereby creating a need for quality sampling and estimation methods. Geospatial mapping of swine damage within a subset of sensitive wetland sites on the APAFR gave us the opportunity to conduct Monte Carlo simulations to optimize line intercept transect spacing (sampling intensity) and to compare estimation methods. This aspect of fully mapping and enumerating field situations for assessing sampling and estimation methods is relatively uncommon, and made all of our "field" observations exact without observational error.

The TLM, which treated transect data as if it came from one long transect, was clearly the better estimation method. It had higher quality estimates of damage, with uniformly lower RRMSEs and biases than the EWM. The EWM equally weighted the data from all transects irrespective of the distances covered. Interestingly, RRMSE for the EWM varied little across inter-transect spacings for all but two sites, whereas RRMSE for the TLM increased as transect spacing increased (transect density decreased), although estimation quality always remained higher than for the EWM. We would expect to observe similar results between the two estimation methods when transect lines are of nearly equal lengths, as in the case of site 3 (Tables 2 and 3).

Sites 3 and 7 had the lowest actual percent damages, which may have contributed to higher RRMSE's for these two sites, especially for the TLM. Because there was an inverse relationship between true percent damage and RRMSE, with RRMSE decreasing as true percent damage increased, a wider transect spacing might be acceptable when the actual amount of damage is higher. However, the damage level in the field may not be readily discernible prior to sampling.

There were diminishing improvements to estimation quality for the TLM once transect spacing width decreased below $5 \mathrm{~m}$. Expectedly, 1-m spacing produced the highest quality estimates, but this spacing is the least likely to be practical in the field, and would also be the most likely to result in damage to fragile habitats. When transect spacing increased beyond $5 \mathrm{~m}$, the estimation quality appeared to decrease exponentially (Fig. 2). Therefore, an inter-transect spacing of $5 \mathrm{~m}$ would be an optimal starting point when designing a sampling plan for estimating damage, with practical, logistical, and economic considerations determining final design details. A further sense of relative accuracy of the 5-m spacing and TLM estimation was demonstrated when we compared damage estimates from all individual simulation iterations for all sites with the associated true damage proportions. Two-thirds of the estimates across all individual simulation iterations using 5-m spacing and TLM estimation were within 0.001 of the true damage proportion. We also recognize that sampling scales can vary widely. Instead of the $1 \mathrm{~m}$ scale for minimum inter-transect spacing we considered, other applications may call for a much different minimum inter-transect spacing (e.g., $1 \mathrm{~km}$ ). Nevertheless, the concepts from our results can be scaled to fit many applications.

Besides providing essential information for assessing the need for, or efficacy of swine management programs, accurate estimates of damage levels also provide information necessary for estimating swine damage in an economic context and for assessing the benefit-costs of management actions. Habitat valuation methods have been well documented and applied to swine damage assessments; the benefit (or monetary value of the reduction in swine damaged habitat) typically far exceeds the costs for swine management (Engeman et al. 2003, 2004, 2007). To make rational management decisions, economic totals should be based on accurate estimates of damage. The economics of sensitive plant damage situations ultimately justifies and determines the nature of the response for management programs.

The sampling and estimation methodology used here to estimate swine damage are generally applicable to other areas of environmental sampling and at different scales, especially in difficult field situations when the sampling target can be a variety of unpredictable sizes and shapes. As an example, habitat sampling from the air allows large tracts of land to be surveyed, but aerial surveys can be very expensive to conduct, especially when using a helicopter. Conversely, costs for surveys using line intercept procedures might be contained and estimation optimized through application of the conceptual results identified here. Similarly, when sampling within specialty crops, the act of sampling can impact yields. Thus, a means to optimize sampling with estimation quality is a valuable tool.

Acknowledgments Field research was supported through interagency agreement 08-7483-0707(IA) between the National Wildlife Research Center and the Avon Park Air Force Range.

\section{References}

Bratton SP (1977) Wild hogs in the United States - origin and nomenclature. In: Wood GW (ed) Research and management of wild hog populations. The Belle W. Baruch Forest Science Institute of Clemson University, Georgetown, pp 1-4

Choquenot D, McIlroy J, Korn T (1996) Managing vertebrate pests: feral pigs. Bureau of Resource Sciences, Australian Government Publishing Service, Canberra

Engeman RM, Sugihara RT (1998) Optimization of variable area transect sampling using Monte Carlo simulation. Ecology 79:1425-1434 
Engeman RM, Sugihara RT, Pank LF, Dusenberry WE (1994) A comparison of plotless density estimators using Monte Carlo simulation. Ecology 75:1769-1779

Engeman RM, Constantin B, Nelson M, Woolard J, Bourassa J (2001) Monitoring changes in feral swine population and spatial distribution of activity. Environ Conserv 28:235-240

Engeman RM, Smith HT, Shwiff SA, Constantin BU, Nelson M, Griffin D, Woolard J (2003) Prevalence and economic value of feral swine damage to native habitat in three Florida state parks. Environ Conserv 30:319-324

Engeman RM, Smith HT, Severson R, Severson MA, Woolard J, Shwiff SA, Constantin BU, Griffin D (2004) Damage reduction estimates and benefit-cost values for feral swine control from the last remnant of a basin marsh system in Florida. Environ Conserv 31:207-211

Engeman RM, Stevens A, Allen J, Dunlap J, Daniel M, Teague D, Constantin B (2007) Feral swine management for conservation of an imperiled wetland habitat: Florida's vanishing seepage slopes. Biol Conserv 134:440-446

Florida Natural Areas Inventory (FNAI) (2010) Guide to the natural communities of Florida. Florida Natural Areas Inventory and Florida Department of Natural Resources, Tallahassee

Harper MG, Trame AT, Hohmann MG (1998) Management of herbaceous seeps and wet savannas for threatened and endangered species. USACERL Technical Report 98/70. US Army Corps of Engineers, Washington, DC
Littell RC, Milliken GA, Stroup WW, Wolfinger RD (1996) SAS system for mixed models. SAS Institute, Cary

Nielson R, Sugihara RT, Boardman T, Engeman RM (2004) Optimization of ordered distance sampling. Environmetrics 15:119-128

Orzell SL (1997) Natural areas inventory of Avon Park Air Force Range in Polk and Highlands counties Florida. Unpublished report to US Air Force

Patil SA, Burnham KP, Kovner JL (1979) Nonparametric estimation of plant density by the distance method. Biometrics 35:597-604

Pielou EC (1977) Mathematical ecology. Wiley, New York

Seward N, VerCauteren K, Witmer G, Engeman R (2004) Feral swine impacts on agriculture and the environment. Sheep Goat Res J 19:34-40

Slocum M, Platt WJ, Beckage B, Orzell SL, Taylor W (2010) Accurate assessment quantification of seasonal rainfall and associated climate wildfire relationships. J Appl Meterol Climatol 49:2559-2573

USDA/Wildlife Services/National Wildlife Research Center (2009) Implementation and evaluation of management tools to reduce feral swine damage to sensitive plant sites at Avon Park AFR, Florida. Annual Report, Year 1 to U.S. DoD/Avon Park Air Force Range

White N, Engeman RM, Sugihara RT, Krupa HW (2008) A comparison of plotless density estimators using Monte Carlo simulation on totally enumerated field populations. BMC Ecol 8(6):1-11

Wood GW, Barrett RH (1979) Status of wild pigs in the United States. Wildl Soc Bull 7:237-246 